\title{
ОЦЕНКА РАЗВИТИЯ ОПЕРАЦИЙ БАНКА ПО ПРИВЛЕЧЕНИЮ ФИНАНСОВЫХ РЕСУРСОВ
}

\author{
(c) 2018 Савинова Валентина Андреевна \\ доктор экономических наук, профессор кафедры Финансы и кредит \\ Самарский государственный экономический университет \\ 443090, г. Самара, ул. Советской Армии, д. 141 \\ E-mail: SavinovaVA@mail.ru \\ (C) 2018 Борлакова Татьяна Евгеньевна \\ преподаватель кафедры Финансы и кредит \\ Самарский государственный экономический университет \\ 443090, г. Самара, ул. Советской Армии, д. 141 \\ E-mail: borlakova@bk.ru
}

Рассматриваются операции банков по формированию финансовых ресурсов на основе депозитной политики. как финансового инструмента развития банковской системы. Особое место уделяется сбережениям населения как финансовому инструменту развития банков и банковской системы.

Ключевые слова: ресурсы, ресурсная база, финансовые ресурсы, депозиты, сбережения, ценные бумаги, депозитная политика, кредитные ноты, облигации.

Операции по привлечению средств, выполняемые коммерческими банками и направленные на формирование ресурсной базы, покрывают большую часть потребности в денежных ресурсах для осуществления банками активных операций, прежде всего кредитных. Одним из важнейших видов ресурсов в банковской деятельности рассматриваются привлеченные ресурсы. Операции по формированию банковских ресурсов (пассивные операции) играют важную роль в развитии каждого коммерческого банка.

Во-первых, стабильность банковских ресурсов, их объемы и структура являются важнейшими факторами ликвидности и надежности банка.

Во-вторых, количество и качество ресурсной базы в решающей степени определяют объемы активных операций, обеспечивающих получение доходов и прибыли банка.

Важная экономическая и социальная роль пассивных операций банков проявляется в мобилизации свободных денежных средств хозяйствующих субъектов и населения на цели удовлетворения потребности экономики в основном и оборотном капитале, трансформации сбережений в производственные и жилищные инвестиции.

Выделяются две группы пассивных операций:

1) включает операции банков по формированию собственных ресурсов, которые не требу- ют возврата, поскольку им принадлежат;

2) включает операции по формированию привлеченных средств на определенное время, т.е. данные ресурсы являются заемными.

Важность операций банков по привлечению финансовых ресурсов определяется тем, что назначением привлеченных средств является обеспечение потребности банков в ресурсах для осуществления активных операций. Таким образом, пассивные операции и выступают как депозитные. Хозяйствующие субъекты, такие как предприятия реального сектора экономики, особенно субъекты малого и среднего бизнеса, на основе привлечения на рынке временно свободных кредитных ресурсов получают возможность обеспечивать развитие экономических и производственных процессов, повышать свою конкурентоспособность.

В развитии данных процессов важная роль отводится сбережениям населения. Для банков, которые не имеют достаточных источников привлечения ресурсов, основным источником их формирования выступают именно рынки сбережений. Следует отметить, что рассматриваемые источники являются наиболее востребованными, поэтому, как правило, банки формируют единую концепцию их привлечения. Для этих целей проводятся аналитические исследования объемов рынка сбережений, выявляются предпочтения населения в надежности разме- 
щения кредитной организацией средств, размеров доходов сбережений, их численности. В этой связи можно констатировать, что возможности банка в привлечении ресурсов характеризуют доверие клиентов, в первую очередь населения, и профессиональный подход его руководства и сотрудников.

Привлеченные и собственные средства используются банком неоднозначно. Так, привлеченные ресурсы обеспечивают его развитие, в то время как собственные средства обеспечивают гарантии банка перед контрагентами по выполнению его обязательств. В качестве их правового обеспечения выступают:

- требования к размеру уставного капитала;

- предельный размер его не денежной части;

- требования к минимальному размеру собственных средств;

- отзыв Банком России лицензии в случае, если ниже двух процентов становятся значения всех нормативов.

Обеспечение стабильного и надежного функционирования банковской системы в России посредством коммерческих банков обусловливается научно-обоснованной банковской политикой. Составным элементом банковской политики является депозитная политика.

Теория финансов рассматривает депозитную политику как сложное явление и характеризует ее как стратегию и тактику банка при осуществлении им деятельности, направленной на привлечение ресурсов на возвратной основе, а также при организации и управлении депозитным процессом [1]. В этой связи необходимо изучить схему формирования депозитной политики.

Схема депозитной политики включает несколько этапов:

I - формулирование целей и разработка задач депозитной политики;

II - организация необходимых для осуществления рабочих процессов структурных подразделений и наделение банковских работников соответствующими полномочиями;

III - разработка необходимых процедур и финансовых инструментов на цели формирования ресурсов;

IV - организация контрольных мероприятий в процессе осуществления депозитных операций и управление ими.

Рассмотренные этапы формирования депозитной политики тесно взаимосвязаны и только в полном составе могут быть использованы для успешной организации депозитного процесса. Исходя из представленного, сущность депозитной политики, можно рассматривать как одну из составляющих системы управления деятельностью банка.

Функционирование депозитной политики осуществляется на системе основополагающих принципов, включающей общие принципы и специфические принципы.

С.А. Некрасов под общими принципами депозитной политики понимает принципы, единые и для государственной денежно-кредитной политики центрального банка, проводимой на макроэкономическом уровне, и для политики на уровне каждого конкретного банка. К ним следует отнести принципы комплексного подхода, научной обоснованности, оптимальности и эффективности, а также единство всех элементов депозитной политики банка.

K специфическим принципам депозитной политики относятся принципы обеспечения оптимального уровня издержке банка, безопасности проведения депозитных операций, надежности, поскольку банк, осуществляя аккумуляцию временно свободных денежных средств с целью их последующего размещения, стремиться получить доход не любой ценой, а с учетом реалий рынка, на котором он осуществляет свою деятельность. Соблюдение перечисленных принципов позволяет банку сформировать как стратегические, так и тактические направления в организации депозитного процесса, обеспечив тем самым эффективность и оптимизацию депозитной политики [2].

Кроме принципов кредитной политики, регулирующей ее формирование и использование, в теории рассматривается также понятие границ депозитной политики коммерческого банка [3].

Полагаем, что данный подход актуален в части возможного предела банками временно свободных средств юридических и физических лиц. На наш взгляд, своя собственная депозитная политика должна быть сформирована у каждого банка. Вместе с тем, анализ сложившейся практики показывает, что формирование депозитной базы каждым отдельным банком связано с большим количеством проблем не только субъективного, но и объективного характера и является сложным и трудоемким процессом.

Проблемы субъективного характера охватывают следующие направления: 
1) капитальная база отечественных банков имеет недостаточное развитие, что негативно влияет на формирование собственной депозитной политики;

2) в значительном числе коммерческих банков отсутствует научная и практически обоснованная концепция проведения депозитной политики;

3) качество и уровень менеджмента разных уровней не всегда подготовлены для решения поставленных задач;

4) ограниченный спектр предлагаемых депозитных услуг, отсутствует или низкий уровень разработки исследований депозитного рынка, отсутствующий или неподготовленный уровень маркетинговых исследований и др. В совокупности все это формирует недостатки в развитии депозитных процессов или операций.

Проблемы объективного характера охватывают следующие направления:

1) низкая межбанковская конкуренция;

2) негативное воздействие отдельных зарубежных стран на состояние российского денежного рынка;

3) нестабильная экономическая ситуация.

Таким образом, депозитными называются операции банков по привлечению денежных средств юридических и физических лиц во вклады на различные временные периоды. Основную часть таких операций составляет пассивные операции, формируемые значительную часть банковских ресурсов. От эффективности и надежности организации таких операций, в конечном счете, зависит устойчивость функционирования коммерческих банков.

В современных условиях проблема формирования ресурсов приобретает первостепенное значение. В значительной степени это вызвано тем, что российская экономика подвержена высокой зависимости от ряда факторов: выставляемых рядом государств санкций, неблагоприятного состояния рыночной конъюнктуры и др.

Основную деятельность банк осуществляет за счет привлеченных и заемных средств, которые составляют преобладающую часть банковских ресурсов. Как указывалось выше, их общая величина составляет от $70 \%$ до $90 \%$ от всех ресурсов банка, поэтому роль привлеченных и заемных ресурсов исключительно велика.

Привлеченные средства формируются при помощи следующих банковских операций:

- открытия и ведения счетов юридических лиц, в том числе банков-корреспондентов;

- привлечения во вклады и депозиты денежных средств физических и юридических лиц.

Рассмотрим объем и структуру привлеченных кредитными организациями средств. (табл. 1.).

Как видно из представленных данных, операции по привлечению ресурсов оказывают большое влияние на развитие кредитной системы. Можно выделить следующие направления положительного воздействия на формирование банковской системы и экономики в целом. Так, ресурсная база в решающей степени определяет через банковскую систему потребности экономики в необходимом для развития капитале. Ликвидность и надежность банка формируется только при наличии банковских ресурсов, напрямую влияющих на величину полученной прибыли.

Из данных табл. 1. видно, что на формирование ресурсов банков в решающей степени оказывают влияние сбережений населения, темпы роста которых превосходят динамику привлечения средств юридических лиц.

Вместе с тем рынок депозитов для юридических лиц, как правило, предлагает более широкую линейку предоставляемых услуг, и более привлекательные ставки для среднесрочного размещения свободных ресурсов. Следует отметить, что депозиты для физических лиц и депозиты для юридических лиц не имеют значительных отличий. Однако депозиты для юридических лиц имеют отдельные преимущества. К ним можно отнести следующие:

Таблица 1. Объем и структура привлеченных кредитными организациями в России средств

\begin{tabular}{|c|c|c|c|c|}
\hline \multirow{2}{*}{ Период } & \multicolumn{2}{|c|}{ Вклады (депозиты) физических лиц } & \multicolumn{2}{c|}{ Средства юридических лиц } \\
\cline { 2 - 5 } & Сумма, млрд. руб. & Темп роста, \% & Сумма, млрд. руб. & Темп роста, \% \\
\hline 01.01 .2015 & 18552,7 & 100,0 & 17007,9 & 100,0 \\
\hline 01.01 .2016 & 23219,1 & 125,1 & 19018,2 & 111,8 \\
\hline 01.01 .2017 & 24200,3 & 104,2 & 16385,2 & 86,2 \\
\hline 01.01 .2018 & 25897,4 & 107,1 & 17900,4 & 109,2 \\
\hline
\end{tabular}

Источник. Составлено по данным Статистического бюллетеня Банка России 
1) под залог депозитов можно в сжатые сроки получить краткосрочные кредиты; кредиты предоставляются в размере не более $70 \%$ от суммы депозита;

2) открываться депозиты могут в разных валютах, что формирует сбалансированную и низкорискованную «корзину», позволяющую снижать риски при изменении курса валют;

3) снижаются процентные ставки по депозитам в том случае, если досрочно выводятся денежные средства. Однако в отдельных банках ставки могут остаться без изменения.

Необходимо отметить, что на протяжении длительного периода времени для российских банков счета корпоративного сектора рассматривались в качестве наиболее традиционного источника ресурсов. Длительное время доля данного источника превышала долю других пассивов. Размещение свободных ресурсов в депозиты становится предпочтительным и доступным с развитием рыночных методов хозяйствования и финансовых инструментов, приносящих высокую доходность по сравнению с расчетными и текущими счетами.

Увеличение денежных средства на счетах банков обусловлено в основном благоприятной внешнеторговой конъюнктурой, приводящей к высоким денежным остаткам на валютных счетах, а потому чаще всего носят краткосрочный характер. Касаясь вопроса формирования ресурсов для кредитования физических лиц, в том числе и ипотечного кредитования, следует отметить, что большим потенциалом увеличения кредитных ресурсов банка обладают банковские депозиты населения.

При рассмотрении средств физических лиц, как основного источника привлечения финансовых ресурсов Сбербанком России, остановимся на анализе их структуры.

По данным табл. 2., в целом привлечение средств физических лиц за рассматриваемый период увеличилось на 405,9 млн. рублей. Ди- намика срочных вкладов физических лиц по состоянию на начало 2018 года также показывает незначительное увеличение объемов срочных вкладов по сравнению с предыдущим периодом. По данным табл. 2. видно, что в структуре привлечения средств физических лиц преобладающую долю занимают срочные вклады, доля которых находится на уровне 80\%, при этом она сохраняется на протяжении последних двух рассматриваемых периодов. Положительную динамику демонстрируют и «текущий счет/счет до востребования».

Депозиты юридических лиц открываются в основном на срок до 1 года, что вполне объяснимо большей подвижностью ресурсов на счетах хозяйствующих субъектах, поэтому они не могут являться источником привлечения длинных денег для фондирования ипотечного кредитования.

Анализ объемов формирования ресурсов, представленных в табл. 3 и 4 полностью подтверждают особую значимость привлечения средств физических лиц для развития депозитных операций. Так, объем привлеченных средств по физическим лицам на начало 2018 г. составлял 12449,6 млрд. рублей, в то время как привлеченные денежные средства государственных и общественных организаций и прочих корпоративных клиентов в суммовом выражении составили в 2017 г. составляли 7754,6 млрд. рублей, в 2017 г. объемы привлечения снизились до 6235,2 млрд. рублей, или на 20,4\%.

Вместе с тем представляет практический интерес доля отраслевого вклада корпоративных клиентов в формирование привлеченных средств Сбербанка (табл. 4).

Высокий международный кредитный рейтинг Сбербанка: Moody's - Baа1 и Fitch Ratings $\mathrm{BBB}$, позволяет производить заимствования как в России, так и за рубежом, путем выпуска ценных бумаг: бондов, нот, векселей. В этой связи рассмотрим особенности данных источников

Таблица 2. Структура привлечения средств физических лиц Сбербанком

\begin{tabular}{|l|c|c|c|c|}
\hline \multirow{2}{*}{\multicolumn{1}{|c|}{ Показатели }} & \multicolumn{2}{|c|}{ на начало 2018 г. } & \multicolumn{2}{c|}{ на начало 2017 г. } \\
\cline { 2 - 5 } & $\begin{array}{c}\text { Сумма, } \\
\text { млрд. руб. }\end{array}$ & Уд. вес, \% & $\begin{array}{c}\text { Сумма, } \\
\text { млрд. руб. }\end{array}$ & Уд. вес, \% \\
\hline 1. Текущий счет /счет до востребования & 2478,9 & 19,9 & 2415,4 & 20,1 \\
\hline 2. Срочные вклады & 9970,1 & 80,1 & 9627,9 & 79,9 \\
\hline 3. Сделки прямого РЕПО & 0,6 & - & 0,4 & - \\
\hline Всего по физическим лицам & 12449,6 & 100,0 & 12043,7 & 100,0 \\
\hline
\end{tabular}

Источник. По данным консолидированного отчета Сбербанка. 
Таблица 3. Структура привлечения средств государственных и общественных организаций и прочих корпоративных клиентов Сбербанком

\begin{tabular}{|l|c|c|c|c|}
\hline \multicolumn{1}{|c|}{ Показатели } & \multicolumn{2}{c|}{ на 01.01.2017 } & \multicolumn{2}{c|}{ на 01.01.2018 } \\
\hline Государственные и общественные организации & $\begin{array}{c}\text { Сумма, } \\
\text { млрд. руб. }\end{array}$ & Уд. вес, \% & $\begin{array}{c}\text { Сумма, } \\
\text { млрд. руб. }\end{array}$ & Уд. вес, \% \\
\hline 1. Текущий счет /счет до востребования & 147,8 & 44,5 & 134,3 & 29,2 \\
\hline 2. Срочные вклады & 184,2 & 55,5 & 325,3 & 70,8 \\
\hline 3. Сделки прямого РЕПО & 0,6 & - & 0,4 & - \\
\hline Всего по физическим лицам & 332,0 & 100,0 & 459,6 & 100,0 \\
\hline & & & & \\
\hline Прочие корпоративные клиенты & & & & 30,5 \\
\hline 1. Текущий счет /счет до востребования & 1843,5 & 31,2 & 2226,7 & 67,9 \\
\hline 2. Средства депозитов & 3997,4 & 67,7 & 4957,4 & 1,6 \\
\hline 3. Сделки прямого РЕПО & 71,3 & 14,1 & 110,7 & 100,0 \\
\hline $\begin{array}{l}\text { Всего средств по прочим корпоративным } \\
\text { клиентам }\end{array}$ & 5903,2 & 100,0 & 7295,0 & $\mathrm{X}$ \\
\hline $\begin{array}{l}\text { Всего средств государственных и общественных } \\
\text { организаций и прочих корпоративных клиентов }\end{array}$ & 6235,2 & $\mathrm{X}$ & 7754,6 & \multirow{2}{*}{} \\
\hline
\end{tabular}

Источник. По данным консолидированного отчета Сбербанка России

Таблица 4. Отраслевой вклад в формирование привлеченных средств Сбербанка России

\begin{tabular}{|c|c|c|c|c|c|}
\hline \multirow{2}{*}{$\begin{array}{c}\text { №№ } \\
\Pi / \Pi\end{array}$} & \multirow[b]{2}{*}{ Отрасли экономики } & \multicolumn{2}{|c|}{01.01 .2017} & \multicolumn{2}{|c|}{01.01 .2018} \\
\hline & & $\begin{array}{c}\text { Сумма, } \\
\text { млрд. руб }\end{array}$ & Уд.вес, \% & $\begin{array}{c}\text { Сумма, } \\
\text { млрд. руб }\end{array}$ & Уд.вес, \% \\
\hline 1. & Нефтегазовая & 1363,6 & 7,3 & 2140,8 & 10,8 \\
\hline 2. & Услуги & 863,8 & 4,6 & 1029,5 & 5,0 \\
\hline 3. & Машиностроение и металлообработка & 751,0 & 4,0 & 687,2 & 3,5 \\
\hline 4. & Торговля и общественное питание & 540,2 & 2,9 & 536,1 & 2,7 \\
\hline 5. & Строительство & 335,4 & 1,8 & 367,5 & 1,9 \\
\hline 6. & Металлургическая & 316,2 & 1,7 & 524,2 & 2,6 \\
\hline 7. & Электроэнергетика & 315,6 & 1,7 & 531,7 & 2,7 \\
\hline 8. & Транспорт & 290,2 & 1,6 & 277,4 & 1,4 \\
\hline 9. & Пищевая промышленность и сельское хозяйство & 172,6 & 0,9 & 200,0 & 1,0 \\
\hline 10. & Телекоммуникации & 169,0 & 0,9 & 203,9 & 1.0 \\
\hline 11. & Государственные и муниципальные учреждения & 166,8 & 0,9 & 213,5 & 1,1 \\
\hline 12. & Химическая и нефтехимическая & 98,8 & 0,5 & 127,9 & 0,6 \\
\hline 13. & Операции с недвижимым имуществом & 98,6 & 0,5 & 131,5 & 0,7 \\
\hline 14. & Лесная, деревообрабатывающая & 28,8 & 0,2 & 39,6 & 0,2 \\
\hline \multirow[t]{3}{*}{15.} & Прочие & 723,9 & 3,9 & 743,8 & 3,8 \\
\hline & Всего средства корпоративных клиентов & 18684,8 & 100,0 & 19798,3 & 00,0 \\
\hline & Справочно: физические лица & 12449,6 & 66,6 & 12043,7 & 60,8 \\
\hline
\end{tabular}

Источник. По данным консолидированного отчета Сбербанка России 
Таблица 5. Структура выпущенных долговых ценных бумаг

\begin{tabular}{|c|l|c|c|c|c|}
\hline \multirow{2}{*}{$\begin{array}{c}\text { №o } \\
\text { п/п }\end{array}$} & \multicolumn{1}{|c|}{ Виды долговых ценных бумаг } & \multicolumn{2}{|c|}{01.01 .2017} & \multicolumn{2}{|c|}{01.01 .2018} \\
\cline { 3 - 6 } & \multicolumn{1}{|c|}{$\begin{array}{c}\text { Сумма, } \\
\text { млрд. руб }\end{array}$} & Уд.вес,\% & $\begin{array}{c}\text { Сумма, } \\
\text { млрд. руб }\end{array}$ & Уд.вес,\% \\
\hline 1. & Сберегательные сертификаты & 482,6 & 41,8 & 577,7 & 41,9 \\
\hline 2. & $\begin{array}{l}\text { Ноты участия в кредитах, выпущенных в } \\
\text { рамках МNТ-программы Сбербанка }\end{array}$ & 473,9 & 40,8 & 607,0 & 44,3 \\
\hline \multirow{2}{*}{3.} & Облигации, выпущенные: & 84,3 & 7,2 & 70,1 & 5,0 \\
& - на внутренний рынок & 21,1 & 1,8 & 34,5 & 2,5 \\
\hline 4. & Векселя & 92,4 & 8,0 & 80,7 & 5,8 \\
\hline 5. & Облигации, выпущенные в рамках программы & 5,5 & 0,4 & 7,2 & 0,5 \\
\hline & секьюритизации ипотечных кредитов & 1161,0 & 100,0 & 1378,5 & 100,0 \\
\hline
\end{tabular}

Источник. По данным консолидированного отчета Сбербанка России

привлечения финансовых ресурсов Сберегательным банком (табл. 5).

Анализ данной табл. 5 показал прирост объемов привлекаемых ресурсов Сбербанком России на основе выпуска ценных бумаг. Это коснулось в первую очередь сберегательных сертификатов и нот участия, что позитивно повлияло на общие итоги привлечения финансовых ресурсов. Общий объем привлечения финансовых ресурсов за рассматриваемый период увеличился на 217,5 млрд. рублей и составил 1378,5 млрд.рублей.

Наибольшую долю на начало 2017 года занимают сберегательные сертификаты $(41,8 \%)$ и облигации, выпущенные в рамках MNT-программы (Medium Term Notes), которая составляет 40,8\%. Данный прирост объясняется политикой банка в области привлечения ресурсов физических лиц и смещением акцента с вкладной деятельности на выпуск сберегательных сертификатов. Все это позволяет отметить как положительную ситуацию, сложившуюся на рассматриваемый период, и касающуюся значительных структурных изменений в эмиссии ценных бумаг.

Сбербанк также привлекал финансирование в виде синдицированных кредитов и кредитов, субординированных займов как на внутреннем, так и на международном рынке. В конце прошлого года Сбербанк привлек синдицированный кредит в размере 134,8 млн. евро. Отдельно следует выделить разовый субординированный заем размером 500 млрд.руб. на 10 лет под $8 \%$ годовых, полученный Сбербанком в конце 2008 года в рамках закона о дополнительной поддержке финансовой системы РФ. Часть займа была погашена в 2010 году и на данный момент остаточная стоимость составляет 303,3 млрд.руб.
Кроме Сбербанка такие кредиты получили Международный инвестиционный банк и Внешэкономбанк.

Ипотечное кредитование характеризуется длительными сроками его функционирования. В этой связи одним из важнейших вопросов его развития является формирование долгосрочных ресурсов. Снижение дефицита кредитных ресурсов осуществляется на основе различных финансовых инструментов, в частности рефинансирования. Посредством этого инструмента решаются две основных проблемы: формирование долгосрочных ресурсов и уменьшение риска ликвидности [4].

Основными методами привлечения долгосрочных ресурсов являются: продажа пула кредитов, выпуск обеспеченных облигаций и секьюритизация ипотечных кредитов.

Необходимо отметить, что до недавнего периода Сберегательный не использовал данный финансовый инструмент. Причиной тому является возможность банка привлекать средства посредством других финансовых инструментов, как на национальном, так и зарубежном рынках.

Вместе с тем, важным принципом банковской деятельности является соответствие сроков привлечения и сроков размещения финансовых ресурсов. С позиции ипотечного кредитования можно отметить, что рассмотренные источники не отвечают данному требованию, что приводит к существенному разрыву ликвидности.

Таким образом, новые источники привлечения долгосрочных ресурсов, а также возможность вывести с баланса долгосрочные активы в целях уменьшения разрыва ликвидности обеспечивают успешное развитие банкам и банковской системе в целом. 


\section{Библиографический список}

1. Банковское дело. Экспресс-курс: учебное пособие / кол. авт. под ред. О.И. Лаврушина. Москва. 2009. 352 с.

2. Некрасов С.А. Сущность депозитной политики // Социально-экономическое развитие России: проблемы, поиски, решения: науч. сб. по итогам НИР. Саратов. 2009

3. Жуков Е.Ф. Банки и небанковские кредитные организации и их операции: учебник. Москва. 2011.

4. Савинова В.А. Теоретические основы ипотечного жилищного кредитования и современная практика его развития в России //Экономические науки. 2017. № 4 (149). С. 81-86.

Поступила в редакцию 28.08.2018 